\title{
VPI Varnishing Technology Effects on Frequency Characteristics of an Air Core Inductor Used in LISN Circuit Application
}

\author{
Khalil Kanzi *, Majid Kanzi *, and Hamidreza Nafissi *
}

\begin{abstract}
The functional characteristic of LISN circuit, which is used for measurements of conductive noise in mains power line, is basically related to frequency characteristics of passive elements like inductors used in the circuit as well as the frequency response of inductors is highly related to the resins used in the varnishing process. The significant problem in determination of an inductor's frequency characteristic is the intrinsic resistance, inductance and parasitic capacitance. In this triplet, the parasitic capacitance is the major limiting factor of inductor's frequency range. This capacitance depends on inductor design parameters and materials filling the spaces of coil like resin and its coherency after curing process. In this paper, two similar inductors were designed and built. The first inductor was not varnished while the second one was varnished with VPI technology. VPI, or Vacuum, Pressure, Impregnation technology is one of the most reliable methods performing good insulating conditions for electrical circuits and windings based on resins. The measured results show that implying varnishing technology does not significantly affect the frequency response. However, due to mechanical solidity aspects and improved environmental protection, it is better to varnish the inductors.
\end{abstract}

Keywords: High frequency inductor, Parasitic capacitance, EMI filter, VPI, LISN

\section{Introduction}

The amount of noise injected to the mains network is related to the noise source impedance and the mains network impedance. None of these impedances are constant nor are time-invariant. In power electronic circuits, these fluctuations arise from switches while turning ON or OFF [1]. In the measuring process of conductive noise, LISN circuit is used for minimizing the effect of impedance nonconformities as well as contradistinction of commonmode and differential-mode noises. Figure 1 shows a simple model of LISN circuit schematically.

The amplitude and spectral power density of conductive noise in mains power line can be measured by a spectrum analyzer. However, the input impedance of a spectrum analyzer usually is not matched to mains power lines especially in higher frequencies. As a result, a matching circuit would be necessary for these measurements. LISN circuits which are in different types, mainly act as low-pass filters with passive elements in the path of high frequency signals. LISN actually matches the impedance of mains

\footnotetext{
* K.N. Toosi Branch, ACECR, K. N. Toosi University of Technology, Tehran, Iran (khkanzi@gmail.com, mjdknz@gmail.com, nafissi@jdnasir.ac.ir)
}

Received 10 September 2012 ; Accepted 02 January 2013 network to the $50 \Omega$ input impedance of the measurement equipment. The specifications of LISN needed for an appropriate measurement process include [2]:

- The ability of transferring power from source to load

- Providing a low impedance path for noise

- Reducing the effect of source impedance in noise measurements.

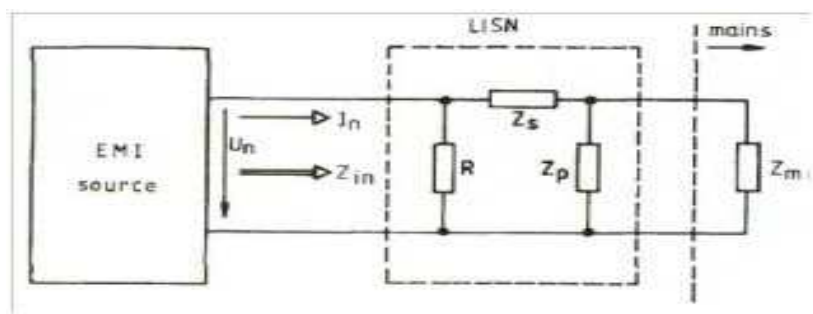

Fig. 1. The application scheme of LISN circuit.

The frequency behavior of LISN circuit depends on the frequency characteristics of passive elements including the inductor. The frequency model of an inductor is depicted in Figure 2 [1]. Rpar in this figure states for the sum of equivalent resistance of coil (copper) loss and the equivalent resistance of core loss which are modeled in series with the inductor coil. The inductance is the sum of self-inductance of each loop and the mutual inductances of 
turns [6]. The parasitic capacitance of inductor which is due to capacitances between loops, between adjacent layers and between coil and the package or shield is modeled as a parallel capacitor, Cpar [6].

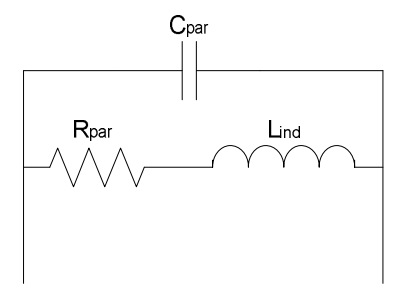

Fig. 2. Frequency model of an inductor.

Evaluating of these parameters by physical dimensions, characteristics of materials and their frequency dependence is considered in several papers [3-7]. For instance, the parasitic capacitance has a major effect on the function of the circuit. In fact, up to the upper frequency limit of conductive noise (namely $30 \mathrm{MHz}$ ), the dielectric constant of most substances does not vary considerably. However, their reactance is affected intensely by frequency. Moreover, the intrinsic resistance is proportional to frequency due to skin and proximity effects. Finally the inductance is a function of the frequency variations of the permeability of magnetic circuit $[7,10]$.

Intrinsic resistance and parasitic capacitance both have harmful impacts on the function of inductors especially in high frequencies [1]. Consequently, the efforts should be concentrated on alleviating their quantity. Two major approaches exist for reducing the parasitic capacitance of an inductor:

The first approach relies on elimination or reduction of inductor's parasitic capacitance using an extra circuit. After construction of the inductor, if the noise is not attenuated adequately by the filter, an extra circuit would be used for this purpose $[12,13]$. This method needs an algorithm for estimating the value of parasitic capacitance with an acceptable precision [14]. Afterwards the compensating circuit should be designed and implemented based on the estimated value [13]

The second method is based on appropriate design of high frequency inductors. As a matter of fact, the type and dimensions of core and the number of layers and turns and their arrangement beside the insulation should be implemented in a manner that the minimum parasitic capacitance could be achieved. Many papers have discussed the calculations of inductor parameters based on the dimensions, the kind of implementation and the material characteristics [3-7, 10]. According to the basic circuit theory, if the internal spaces of an inductor are filled by a resin with permittivity constant greater than the air, the stray capacitance will increase and the frequency response of inductor will generally degrade, although using VPI technology is compulsory in many applications due to electrical and mechanical considerations. In this case, if the frequency response of the inductor would be important, the impact of stray capacitance should be considered precisely. The definite instances to be mentioned are EMI filters and LISN circuits applied in electrical propulsion systems. There are no explanations about the insulating quality of the filling resin in high frequency inductors especially in LISN circuits so far.

A 10A single-phase LISN circuit has been designed and constructed. The detailed design was adopted from [8]. The frequency behavior of LISN circuit was investigated by two types of inductors with the same design. The first type was completed with resin by VPI technology and the second was used without varnish. The frequency characteristics of these two inductor types are compared in section 4 .

\section{VPI Technology}

Varnishing of circuits and inductors is common for mechanical robustness and extra environmental protection. Resin is implied as the main insulation substance for isolating different parts in high voltage elements. Varnishing is implemented also widely for fixing the electrical circuits in systems exposed to shocks and mechanical vibrations. VPI technology basically consists of two overall steps. First, injecting resin into electrical circuit in order to fill all gaps, and then, thermal operations for Curing. Both steps are under constraints which at all form the VPI process. Resins, which are produced and presented to market by several producers, represent diverse electrical, thermal and mechanical qualities after Curing process.

\subsection{The main elements forming the VPI System}

- Resin Container. This container reserves resin and should include a mixer. This system mixes the resin and the thinner material before varnishing in order to extend the concentration of resin to a desired level. Moreover, a heater system is required to increase the temperature of resin up to an appropriate level prior to varnishing operation. These systems should be free of any sparks because resin contains flammable gases. The saving tank can have a small opening for adding resin or for entering maintenance personnel into the tank while 
it needs cleaning.

- Varnishing operation tank. The subject is placed in this tank. The tank has a large opening equipped with an anti-spark system and is connected to a vacuum pump and a Noble gas tank. The resin inlet is normally from the bottom of the tank.

- Vacuum system. This system is used for making vacuum in the varnishing tank. The significant specification of vacuum system is the value of its positive pressure, namely in order of 1 mbar. Moreover, its flow determines the speed of making vacuum.

- Noble gas tank. This tank contains octet (noble) gas which is injected into the varnishing tank. Octet gases are full gases and anti combustion and are implemented for squeezing the resin.

- Thermal furnace. The resin used in VPI technology reaches to the final quality only under a specific thermal cycle named as Curing Process. Implying this thermal cycle needs a heating furnace. The varnished apparatus enters this furnace just after exiting varnishing tank and is exposed to the specified time-thermal cycle.

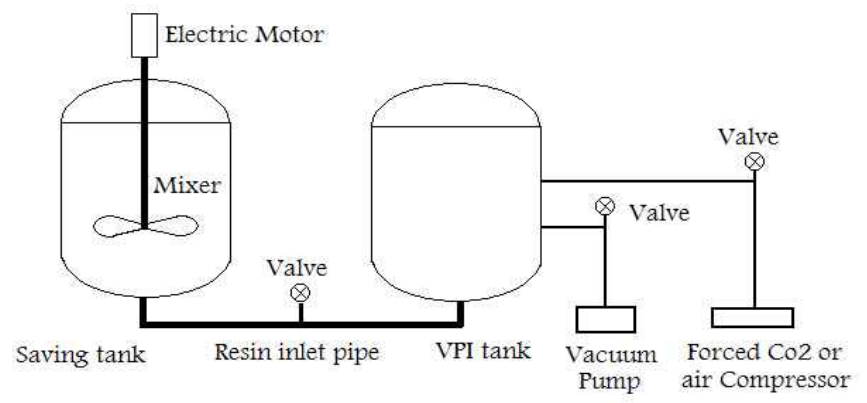

Fig. 3. VPI system schematic

\subsection{The specifications of exploited system}

- Volume of tanks: up to 2000 liters

- Diameters of tanks: app. $110 \mathrm{~cm}$, effective height: $200 \mathrm{~cm}$

- Vacuum pump 1: It should have higher flow rate and higher minimal positive pressure. This pump is implemented initially for faster vacuumizing to a positive pressure level normally less than 100 mbar.

- Vacuum pump 2: It should have lower flow rate and lower minimal positive pressure. This pump is implemented in the second stage for slower vacuumizing to a positive pressure level lower than the first stage, namely under 1 mbar.

- 4 capsule with 44 liters capacity all containing $\mathrm{CO} 2$ gas.

- $\quad$ Compressor with a 300 liters tank. This system is depicted in figure 4 .

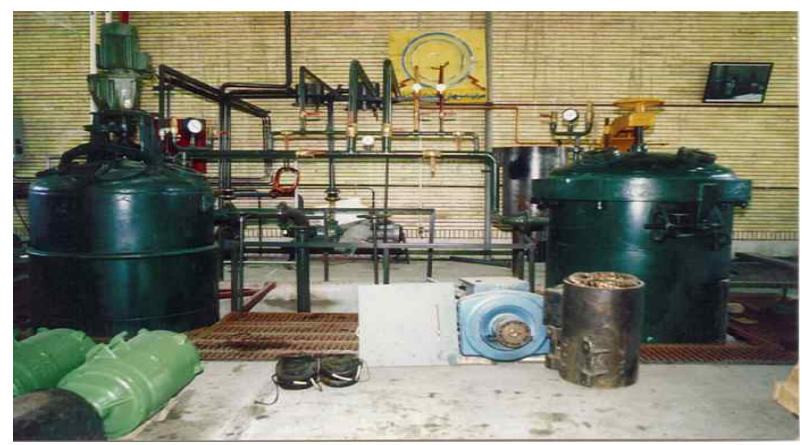

Fig. 4. The exploited VPI system

\subsection{VPI Process}

- Measuring resin's concentration and correcting it while necessary.

- Resin heating.

- Preheating the subject.

- Placing the subject in the varnishing tank.

- Vacuumizing the varnishing tank.

- Transferring of resin from resin container to varnishing tank up to an appropriate level.

- Implying positive pressure higher than atmosphere pressure using noble gases.

- Transferring the varnished subject to heating furnace for the Curing process.

\subsection{Technical specifications of used resin (CC-1144)}

\subsection{VPI quantities for $\mathrm{CC}-1144$ resin}

- Preheating of subject(coil) up to $105 \sim 110^{\circ} \mathrm{C}$ and putting it in varnishing tank.

- Vacuumizing the varnishing tank to $4 \mathrm{mmHg}$ in 20 minutes.

- During this time, the temperature of coil should not decrease from $50^{\circ} \mathrm{C}$.

- Entering resin into varnishing tank gradually so that the level of resin is $2 \mathrm{~cm}$ over the coil.

- The pressure of vacuum should be maintained at the specified level for 30 minutes.

- Removing the vacuum and implying a 6 8 Atm pressure for 20 minutes.

- Removing the excess pressure and exiting coil from the varnishing tank then placing it in the heating furnace for Curing. 
Table 1. CC-1144 resin technical specifications

\begin{tabular}{|c|c|c|c|c|}
\hline \multirow[t]{2}{*}{ General } & Code number & \multicolumn{3}{|c|}{$\begin{array}{l}\text { DOLPHON CC-1144 } \\
\text { Modified Polyester }\end{array}$} \\
\hline & Application & \multicolumn{3}{|c|}{ VPI and DIP } \\
\hline \multirow{6}{*}{$\begin{array}{l}\text { Physical } \\
\text { properties }\end{array}$} & $\begin{array}{c}\text { Specific gravity } \\
\text { at } 25^{\circ} \mathrm{C}\end{array}$ & \multicolumn{3}{|c|}{$1200 \pm 50 \mathrm{gr} / \mathrm{lt}$} \\
\hline & $\begin{array}{l}\text { Viscosity ford cup } \\
\text { N.4 at } 25^{\circ} \mathrm{C}\end{array}$ & \multicolumn{3}{|c|}{$220 \sim 300$} \\
\hline & Flash point & \multicolumn{3}{|c|}{$>165^{\circ} \mathrm{C}$} \\
\hline & Gel time at $100^{\circ} \mathrm{C}$ & \multicolumn{3}{|c|}{$100 \sim 190 \mathrm{~min}$} \\
\hline & Gel time at $110^{\circ} \mathrm{C}$ & \multicolumn{3}{|c|}{$20 \sim 60 \mathrm{~min}$} \\
\hline & Thermal life & \multicolumn{3}{|c|}{$200^{\circ} \mathrm{C}$} \\
\hline \multirow{2}{*}{$\begin{array}{c}\text { Curing } \\
\text { properties }\end{array}$} & Temperature ${ }^{\circ} \mathrm{C}$ & 175 & $65 \sim 155$ & $155 \sim 120$ \\
\hline & Time at oven hr & $1 \sim 3$ & $2 \sim 5$ & $4 \sim 6$ \\
\hline \multirow{5}{*}{$\begin{array}{l}\text { Electrical } \\
\text { properties }\end{array}$} & Dielectric strength & \multicolumn{3}{|c|}{$2500 \mathrm{Volt} / \mathrm{mil}$} \\
\hline & $\begin{array}{c}\text { Dielectric } \\
\text { constant, } 1 \mathrm{KHz} \text { at } \\
25^{\circ} \mathrm{C}\end{array}$ & \multicolumn{3}{|c|}{2.5} \\
\hline & $\begin{array}{c}\text { Volume resistivity } \\
\text { at } 25^{\circ} \mathrm{C}\end{array}$ & \multicolumn{3}{|c|}{$2 \mathrm{E} 16 \Omega / \mathrm{cm}$} \\
\hline & $\begin{array}{c}\text { Surface resistivity } \\
\text { at } 25^{\circ} \mathrm{C}\end{array}$ & \multicolumn{3}{|c|}{$2 \mathrm{E} 14 \Omega / \mathrm{cm}$} \\
\hline & $\begin{array}{c}\text { Dissipation factor, } \\
1 \mathrm{KHz} \text { at } 25^{\circ} \mathrm{C}\end{array}$ & \multicolumn{3}{|c|}{0.008} \\
\hline
\end{tabular}

\section{Design and Construction of LISN Circuit}

An LISN circuit according to CISPR 16-1 with the Vnetwork specification $50 \Omega / 50 \mu \mathrm{H}+5 \Omega$ is shown in Fig. 5:

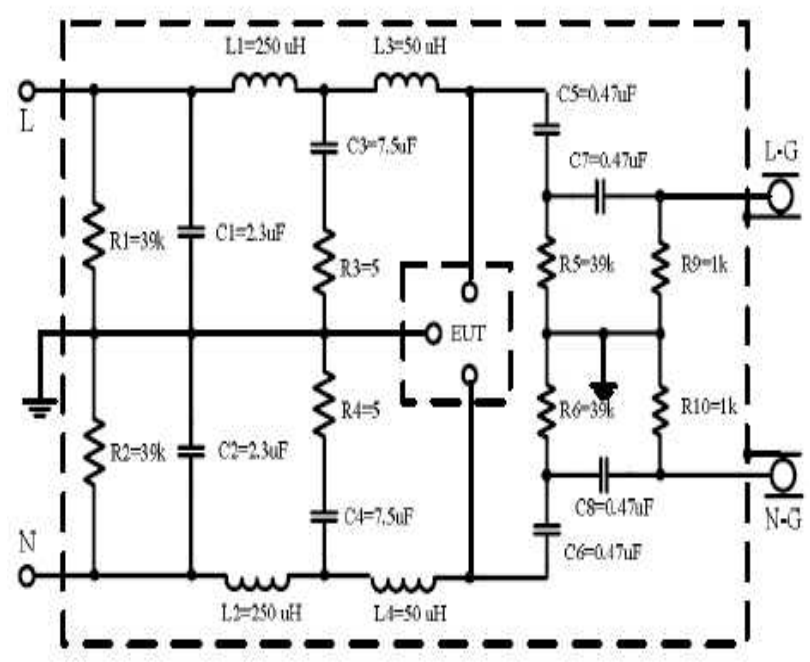

Fig. 5. An LISN circuit; $50 \Omega / 50 \mu \mathrm{H}+5 \Omega \mathrm{V}$ - network

As it could be seen, there are resistors, capacitors and inductors in the circuit

\subsection{Selecting resistors types}

All resistors are of carbon film type because the frequency characteristic of this type of resistors is independent from frequency up to $30 \mathrm{MHz}$. R3 and R4 are $5 \mathrm{~W}$ and all others are $1 \mathrm{~W}$.

\subsection{Selecting capacitors type}

There are two types of capacitors used in this circuit: First is metalized polypropylene type. $\mathrm{C} 1$ to $\mathrm{C} 4$ are from this type. Second is metalized polyester type. C5 to C8 are from this type.

\subsection{Selection, design and construction of inductors}

- The required equations for design are adopted from previous papers [8] and the following results were implemented for construction:

- The inductor's current density was selected about 3 $\mathrm{A} / \mathrm{mm} 2$. Consequently, for $10 \mathrm{~A}$ current a $2.10 \mathrm{~mm}$ wire was used. It was a double coating wire of class H.

- The bobbin was fabricated from a cylindrical threaded fiber material of class $\mathrm{H}$ and specified dimensions.

- According to design equations of air core inductors, a $250 \mu \mathrm{H}$ inductor needs 96 turns wounded in three layers, and a $50 \mu \mathrm{H}$ inductor has 50 turns in one layer.

- For a 3-layer inductor, the center-to-center distance of adjacent turns is about $3.6 \mathrm{~mm}$. This selection is due to the higher stray capacitance of 3-layer inductor compared to single layer one. As a result, the selected distance was larger in order to reduce this capacitive property.

- The inter-layer space of $1 \mathrm{~mm}$ was produced using class H Nomex insulator.

- For a single layer inductor, the selected center-tocenter distance between two adjacent turns was about $.2 .7 \mathrm{~mm}$.

- After design, the inductors were built in two methods, namely with varnishing using VPI technology and without varnishing.

Two $250 \mu \mathrm{H}$ inductors produced with this method are depicted in figure 6.

To investigate the difference between these two inductors and the effect of varnishing, the inductors' parameters should be compared via measurement and estimation. This method has been explained in [14]. Measuring the 
impedance of inductor with an impedance analyzer in a frequency range covering the bandwidth around resonance frequency and then estimation of inductor's parameters according to frequency variations has been considered.

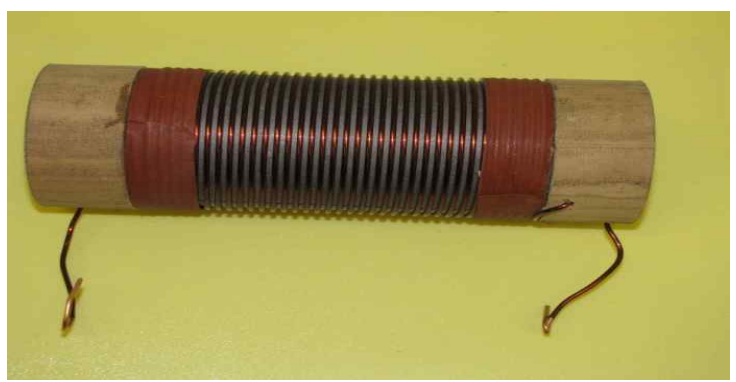

(a)

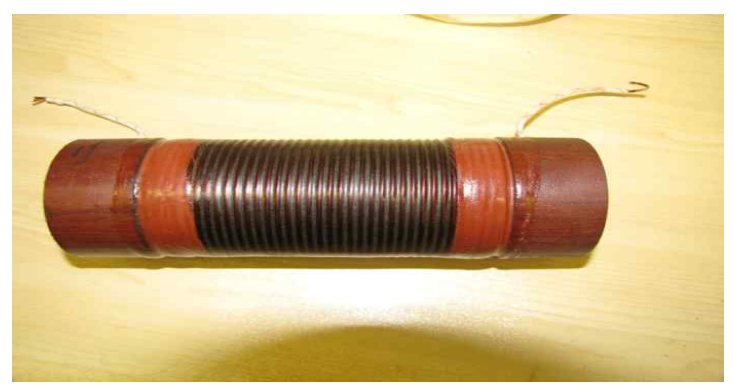

(b)

Fig. 6. $25 \mu \mathrm{H}$ inductors (a) without varnishing (b) after varnishing with VPI technology

Measurements show that varnishing, although completely coherent, does not affect the inductor's impedance frequency characteristic considerably. Albeit as apparent in figure 7, there exist some undesired effects namely a tiny reduction in inductor's resonance frequency (about $10 \mathrm{KHz}$ ), besides, a $4 \mathrm{k}$ decrease in maximum impedance magnitude in resonance frequency.

\section{Comparing the Parameters of Two Inductors}

In order to compare two inductors and distinguish their difference, parameters $L_{i n d}, R_{p a r}$ and $C_{p a r}$ should be estimated for these two inductors according the model of figure 2 and then compared. Depending on the parametric estimation algorithm discussed in [14], for a $250 \mu \mathrm{H}$ inductor and a $3 \mathrm{~dB}$ bandwidth around the resonance frequency, the parameters have been estimated as follows:

\subsection{Parameters of the $250 \mu \mathrm{H}$ inductor without varnishing}

The resonance frequency for this inductor is about 1.004
$\mathrm{MHz}$ in which the magnitude of inductor's impedance is 36 $\mathrm{k} \Omega$. The estimated parameters of the model of figure 2 in the $3 \mathrm{~dB}$ bandwidth from the starting frequency 0.9866 $\mathrm{MHz}$ up to the ending frequency $1.0242 \mathrm{MHz}$ have been estimated and illustrated in figures 8 to 12 .

The magnitude of the resistance in the estimation frequency range is between $34.3589 \Omega$ and $82.9865 \Omega$.

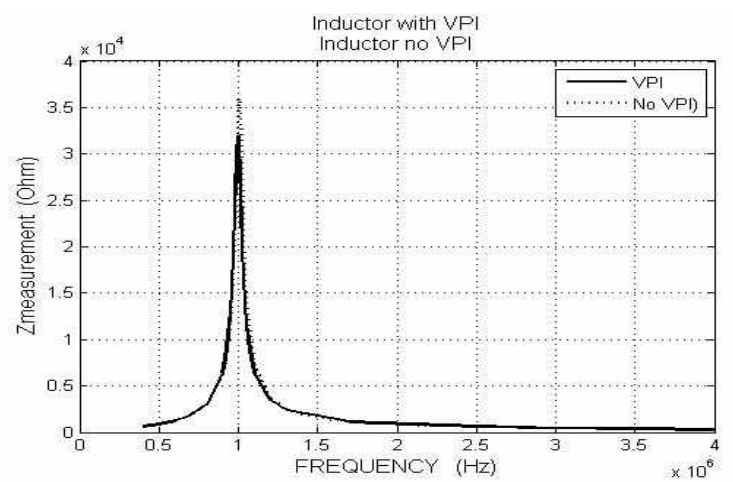

(a)

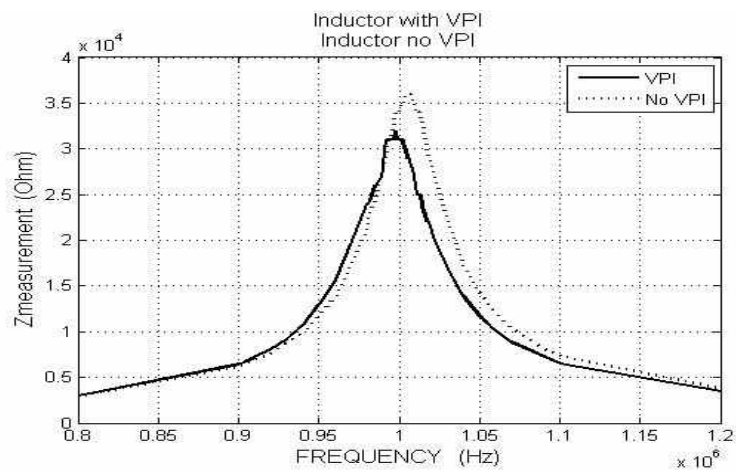

(b)

Fig. 7. Impedance variations of a normal inductor and a varnished inductor with frequency(a) in a wide frequency range $(b)$ in a narrow frequency range

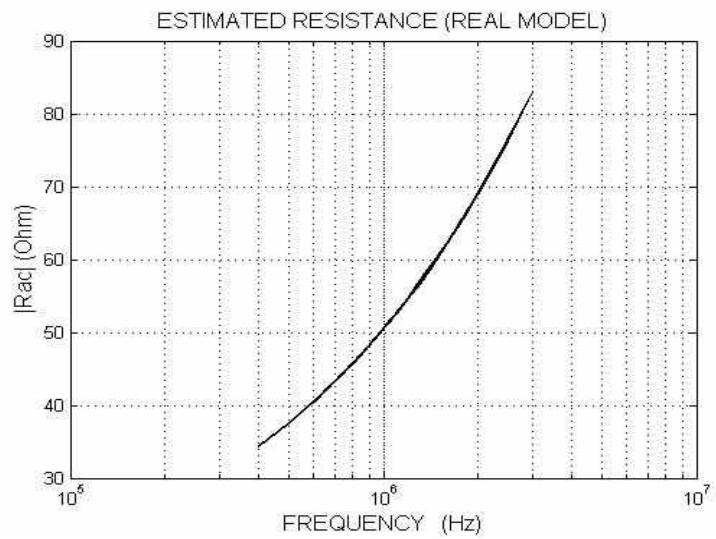

Fig. 8. Estimated resistive characteristic of the inductor without varnishing 


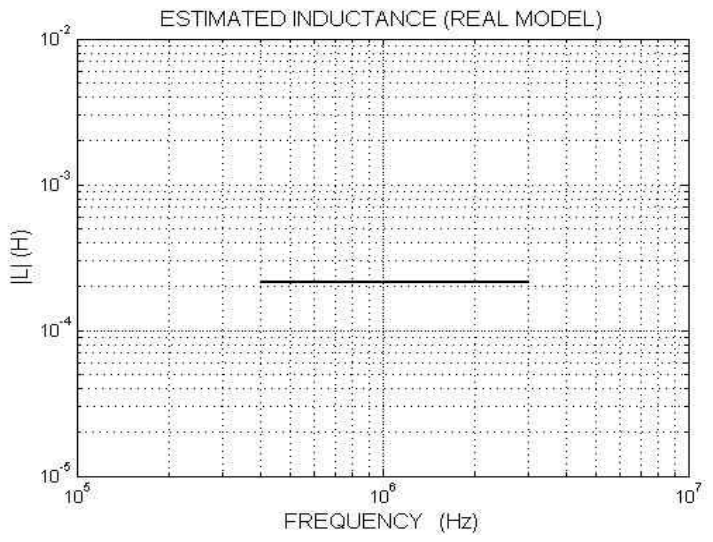

Fig. 9. Estimated inductive characteristic of the inductor without varnishing

The estimated inductance is about $213.6 \mu \mathrm{H}$.

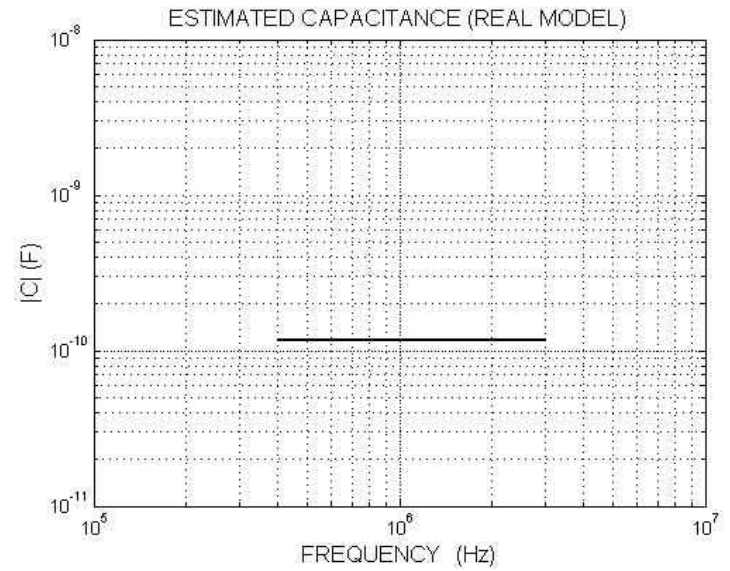

Fig. 10. Estimated capacitive characteristic of the inductor without varnishing

The estimated capacitance is about $117.48 \mathrm{pF}$.
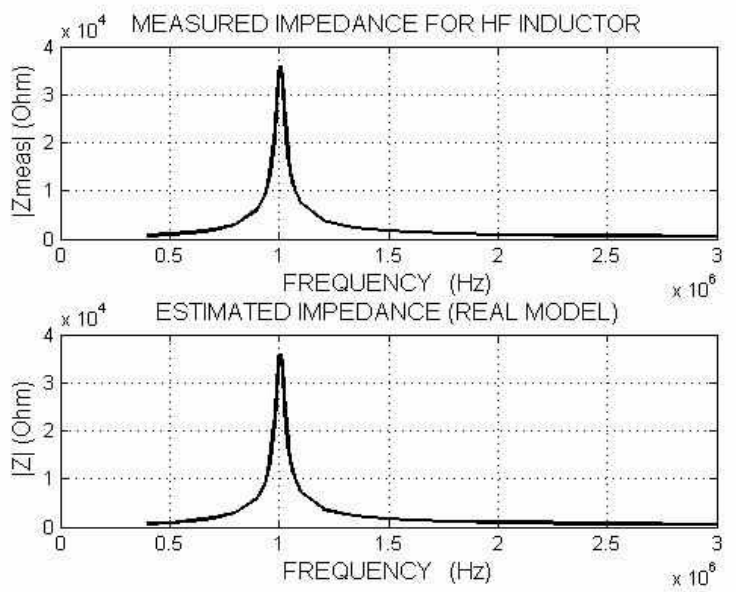

Fig. 11. Measured and estimated impedance characteristic of the inductor without varnishing

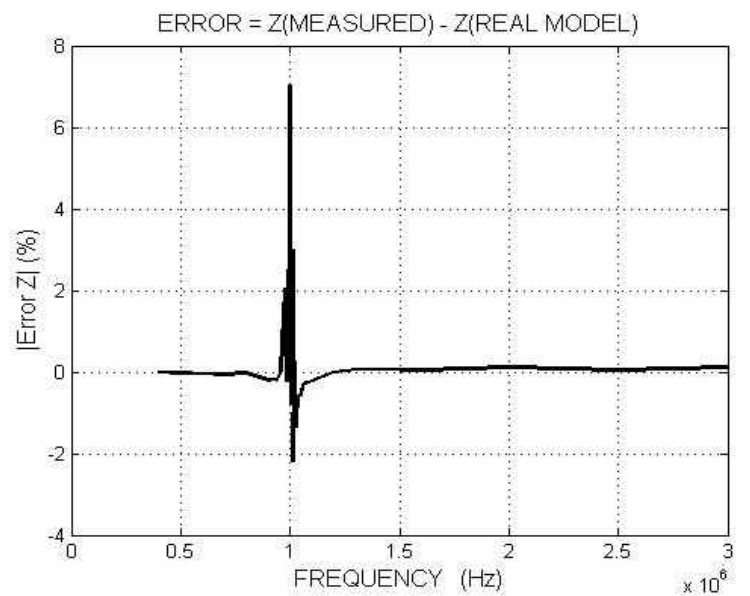

Fig. 12. Error characteristic of measured and estimated impedance for the inductor without varnishing

The root mean square error of measured and estimated impedance is about 0.2104 per cent.

\subsection{Parameters of the $250 \mu \mathrm{H}$ inductor varnished with VPI technology}

The resonance frequency for this inductor is about 0.997 $\mathrm{MHz}$ in which the magnitude of inductor's impedance is 32 $\mathrm{k} \Omega$. The estimated parameters of the model of figure 2 in the $3 \mathrm{~dB}$ bandwidth from the starting frequency 0.9769 $\mathrm{MHz}$ up to the ending frequency $1.0164 \mathrm{MHz}$ have been estimated and illustrated in figures 13 to 17 .

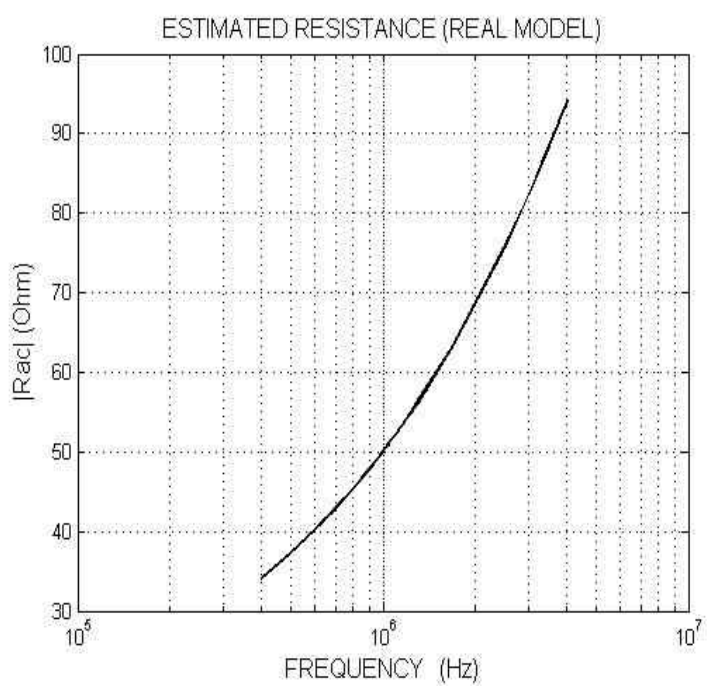

Fig. 13. Estimated resistive characteristic of the inductor varnished with VPI technology

The magnitude of the resistance in the estimation frequency range is between $34.08 \Omega$ and $94.18 \Omega$.

The estimated inductance is about $201.6 \mu \mathrm{H}$. 


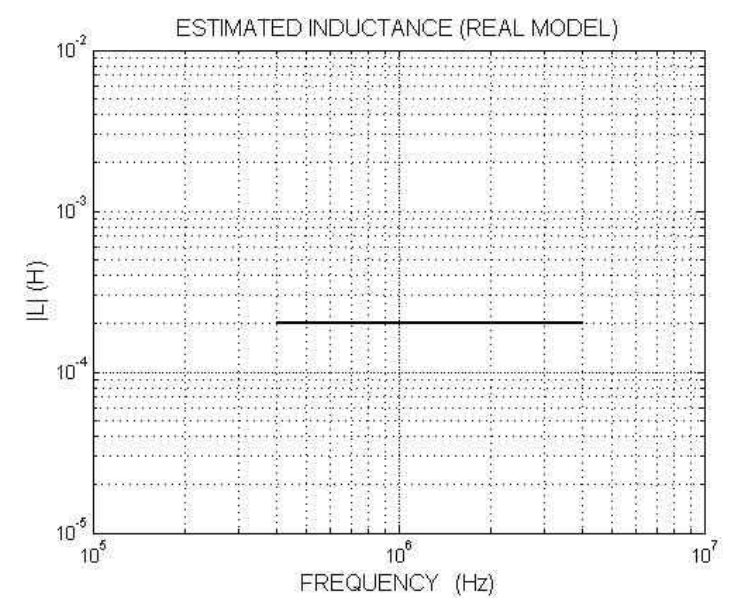

Fig. 14. Estimated inductive characteristic of the inductor varnished with VPI technology

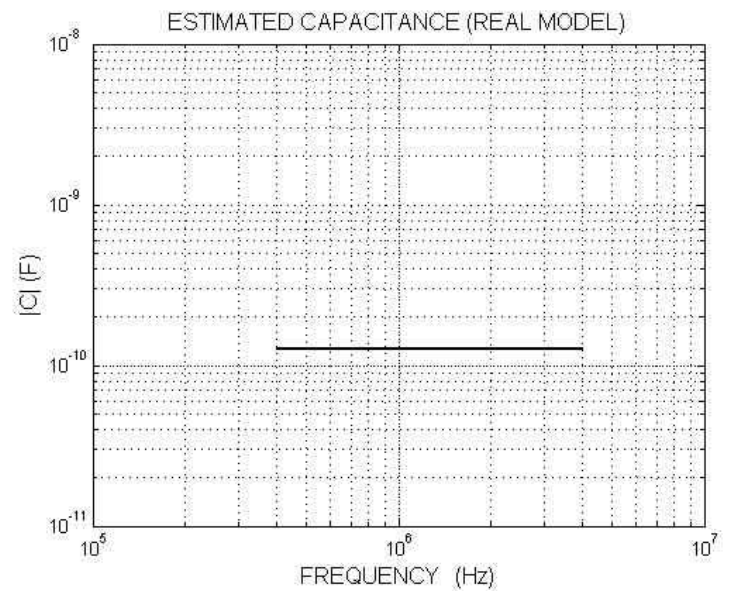

Fig. 15. Estimated capacitive characteristics of the inductor varnished with VPI technology

The estimated capacitance is about $126.03 \mathrm{pF}$.
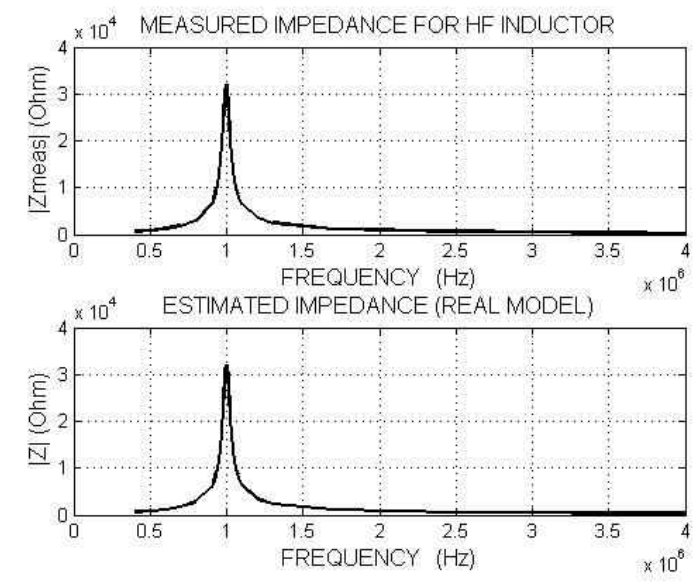

Fig. 16. Measured and estimated impedance characteristic of the inductor varnished with VPI technology

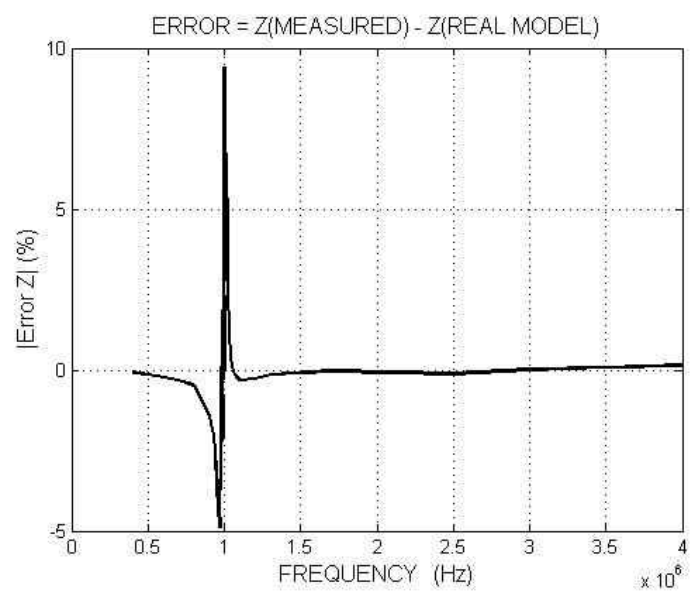

Fig. 17. Error characteristic of measured and estimated impedance for the inductor varnished with VPI technology

The root mean square error of measured and estimated impedance is about 0.3970 per cent.

\subsection{Conclusion of Comparing Inductors' Parameters}

As mentioned before, using resin does not have a major impact on inductor's characteristics especially its high frequency behavior and as the measurements reveal, one can claim that it could have a damaging impact because it reduces the resonance frequency and the impedance magnitude as well. Consequently, resin could be useful for improving the coils' mechanical solidity, enhanced environmental protection and some other features; otherwise it could not affect the overall functionality of the circuit.

\section{Conclusion}

Inductor elements for a single-phase LISN circuit were designed and constructed in two types namely without varnishing and varnished with VPI technology. The characteristics of pressure, vacuum and temperature were adjusted according to resin's datasheet in order to imply a perfect curing process. Next, the inductors' frequency characteristics were compared. The comparison was performed via measurement of impedance magnitude according to frequency and estimating the inductor's model parameters. The comparison showed that there is no major difference between frequency responses of both types of inductors. It could even be claimed that the parasitic capacitance of varnished inductor is a bit greater. The greater capacitance results in reduction of internal resonant frequency and limiting of desired frequency response of 
inductor. This happens due to existence of resin among coil's layers and loops and its insulation coefficient which is greater than air (namely 2.5 times). Consequently, if there is no exigency for using resins owing to mechanical or environmental aspects, it should be avoided in order to manage the extra expenses and time. The inductors were used in an LISN circuit for measuring the conductive noise of a boost converter with PFC whose results will be published in an another paper.

\section{References}

[1] L. Tihanyi, "Electromagnetic Compatibility in Power Electronics", IEEE Press, New York, 1995.

[2] J. Mahdavi , Sh. Kaboli, H.A. Toliyat, "Conducted Electromagnetic Emissions in Unity Power Factor AC/DC Converters; Comparison between PWM and RPWM Techniques", IEEE, Power Electronics Specialists Conference (PESC), USA, 1999.

[3] M. Bartoli, A. Reatti, M. K. Kazimierczuk, " Modeling IronPowder Inductors at High Frequencies", IEEE 00377550 1994.

[4] U. Reggiani, G. Grandi, G. Sancineto, M. K . Kazimierczuk, A. Massarini, "Model of Laminated Iron Core Inductors for High Frequencies" IEEE TRANSACTIONS ON MAGNETICS, Vol. 40, Nos. 4, JULY 2004.

[5] U. Reggiani, G. Grandi, G. Sancineto, M. K . Kazimierczuk, A. Massarini, "High Frequency Small Signal Model of Ferrite Core Inductors" IEEE TRANSACTIONS ON MAGNETICS, Vol. 35, No. 5, SEPT 1999.

[6] U. Reggiani, G. Grandi, G. Sancineto, A. Massarini, "Laminated Iron Core Inductor Model for Time Domain Analysis" PEDS 2001, Indonesia.

[7] A. Massarini, M.K. Kazimierczuk, G. Grandi, "Lumped Parameter Models for Single- and Multiple-Layer Inductors", Pesc96 conf, 1996.

[8] D. Sakulhirirak, V. Tarateeraseth, W. Khan-ngern, N. Yoothanom, "Design of High Performance and Low Cost Line Impedance Stabilization Network for University Power Electronics and EMC Laboratories", PEDS 2007, Bangkok.

[9] C. A. Desoer. E. H. Kuh, "Basic Circuit Theory". McGrawHill Book Company. 1969.

[10] D. K. Cheng, "Field and Wave Electromagnetics". Addison Wesley Publishing Company. 1983.

[11] G. Grandi, M. K. Kazimierczuk, A. Massarini, U. Reggiani, "Stray Capacitances of Single-Layer Solenoid Air-Core Inductors", IEEE TRANSACTIONS ON INDUSTRY APPLICATIONS, Vol. 35, No. 5, September / October 1999.

[12] T. C. Neugebauer. D. J. Perreault, "Parasitic Capacitance Cancellation in Filter Inductors". IEEE. Trans. Power Electronics, Vol. 21, No. 1, January 2006, pp. 282-288.

[13] K.Kanzi, M. Tavakoli Bina, A. Hooshmand Vicki, "Compensation of Parasitic Capacitance of an Inductor for EMI Filtering Applications: Modifications, Analysis and Implementation", IREE Transaction, Vol. 4, No. 5, Part B, October 2009.

[14] K.Kanzi, M. Tavakoli Bina, A. Hooshmand, "Modeling, Design and Test of an EMI Filter Under Conductive Noise to Lower Parastic Losses in Power Electronic Applications", $\mathrm{PhD}$ Thesis, KN Toosi University, Tehran, Iran,2010

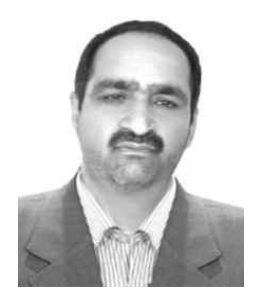

Khalil Kanzi received the B.S degree from K.N.Toosi University and M.Sc from Tarbiat Modaress University in 1984 and 1992 respectively. He received the Ph.D. degree from K. N. Toosi University in Teheran, 2010. He has worked for the ACECR research Institute (K.N.Toosi University branch) in Teheran in the area of $\mathrm{LV} / \mathrm{HV}$ high power electrical machines (Design and realization) such as $\mathrm{AC} / \mathrm{DC}$ Traction motors, $\mathrm{AC} / \mathrm{DC}$ Counter rotating motors in the power of up to $190 \mathrm{kw}$, Eddy current Loads, power electronic and power systems since 1985 . He is now working at the ACECR Institute and his working area is design and realization of conducted EMI filters, LISN circuits, electrical machines and FACTS controllers.

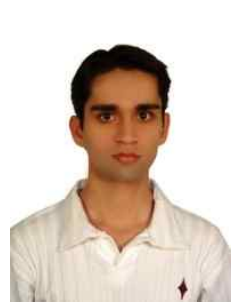

Majid Kanzi received the B.Sc. degree in Electrical Engineering from Islamic Azad University of Tehran and M.Sc. in Power Electronics in Kurdistan University of Iran in 2006 and 2010 respectively. Since 2004, he has been working on research area of power quality in Electrical Power Network and from 2009, on Improving Power Factor and Eliminating the EMI Noise in Switching Power Supplies. He also worked on designing and fabrication of electromechanical devices such as eddy current brake, DC counter rotating motor at the ACECR. His interesting fields are EMC/EMI, power electronic devices and FACTS controllers.

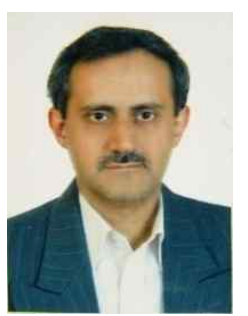

Hamidreza Nafissi received the B.Sc and M.Sc degrees both from K.N.Toosi University in 1988 and 1992 respectively. He has worked for the ACECR Research Institute (K.N.Toosi University branch) in Teheran in the area of telecommunications, solid-state microwave amplifiers, solid-state high-power MW broadcast transmitters (MW, SW and FM), HF high efficiency class-D amplifiers, frequency synthesizers, electronic protection circuits for transmitters, audio processing circuits, a wide variety of switching power supplies, switched mode chargers, dc-dc converters, since 1990. He is now a $\mathrm{PhD}$ student at the Electrical and Computer Engineering Department of Waterloo University. 